RAD Conference Proceedings, vol. 5, pp. 32-36, 2021

ISSN 2466-4626 (online) | DOI: 10.21175/RadProc.2021.06

www.rad-proceedings.org

\title{
YTTRIUM-90 SEPARATION IN CARBONATE MEDIA BY SOLVENT EXTRACTION
}

\author{
Igor Smirnov',2,3*, Ahmed Harb3,4, Igor Balantsev,3, Maria Karavan1,2,3 \\ ${ }^{1}$ Ozersk Institute of Technology, Ozersk, Russia \\ ${ }^{2}$ Khlopin Radium Institute, Russia, St. Petersburg \\ 3Saint Petersburg State University, Russia, St. Petersburg \\ 4Atomic Energy Authority, Hot Laboratories Center, Nuclear Chemistry Department, Egypt, Inshas, Cairo
}

\begin{abstract}
The possibilities of ${ }^{90} \mathrm{Y} /{ }^{\circ} \mathrm{Sr}$ separation from carbonate media are investigated as a green alternative method. Solvent extraction of yttrium and strontium from carbonate solution is studied using several extractants in different organic diluents. 8-hydroxyquinioline and 2,3-dihydroxynaphtalene possess a promising Y/Sr separation. Yttrium and strontium distribution ratios $D$ and separation factors $S F$ are evaluated. $p H$ interval $13-13.5$ is regarded

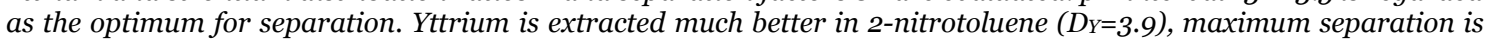
observed in 2-nitrotoluene $S F=195$ at $\mathrm{pH} 13.5$.
\end{abstract}

Key words: Yttrium-9o, Strontium-9o, separation, carbonate media, solvent extraction

\section{INTRODUCTION}

Yttrium-90 $\left(\mathrm{T}_{1 / 2}=64 \mathrm{~h}, \mathrm{E}_{\beta \max }=2.28 \mathrm{MeV}\right)$ is betaemitting radionuclide, it exists in equilibrium with his maternal radionuclide ${ }^{90} \mathrm{Sr}\left(\mathrm{T}_{1 / 2}=28.8 \mathrm{yrs}\right)$ [1]-[3]. Yttrium-90 is of great interest to monitor strontium-90 in natural samples. It is also a therapeutic radioisotope due to its pure $\beta^{-}$-particle emission, its decay produces a stable daughter nuclide $\left({ }^{\circ} \mathrm{Zr}\right.$ ) (Fig. 1), thus yttrium extraction and separation demand is more urgent [1], [4].

Strontium-90 is one of the fission products. It is considered as one of the major heat generators in nuclear waste [1], [5]. The annual world production of ${ }^{90} \mathrm{Sr}$ in nuclear reactors reaches several hundred MCi. Currently, the spent nuclear fuel is processed in a small number of countries, and these countries have capability to develop chemical process for large scale separation of ${ }^{\circ} \mathrm{Sr}$ from spent nuclear fuel [1]-[4], [6], [7].

It is crucial to separate ${ }^{90} \mathrm{Y}$ from ${ }^{90} \mathrm{Sr}$ both for radioecology $\left({ }^{\circ} \mathrm{Sr}\right.$ determination) and medicine ${ }^{{ }^{\circ} \mathrm{Sr}} /{ }^{\circ} \mathrm{Y}$ generators). Various extractants have been developed for ${ }^{\circ} \mathrm{Y}$ extraction and separation from ${ }^{\circ} \mathrm{Sr}$ in acidic media. Peppard et al. in 1957 used dioctylphosphoric acid as the extractant in separation of carrier free ${ }^{90} \mathrm{Y}$ from ${ }^{90} \mathrm{Sr}$ [8]. Then, Mirza in 1968 succeeded to separate ${ }^{90} \mathrm{Y}$ from ${ }^{\circ} \mathrm{Sr}$ by $\beta$-diketone (1-phenyl-3-methyl-4-caprylpyrazolone-5) [9]. Also di-(2-ethyl hexyl)-phosphoric acid (D2EHPA) has been extensively studied, and presented high ${ }^{\circ} \mathrm{Y}$ separation from ${ }^{90} \mathrm{Sr}$. Wike et al. reported about extraction of multicurie levels of ${ }^{90} \mathrm{Y}$ from the ${ }^{90} \mathrm{Sr}$ solution using
D2EHPA [10]-[12]. Crown ethers also have been extensively studied [13], but their main drawback is radio-chemical instability, high cost and third-phase formation tendency [14].

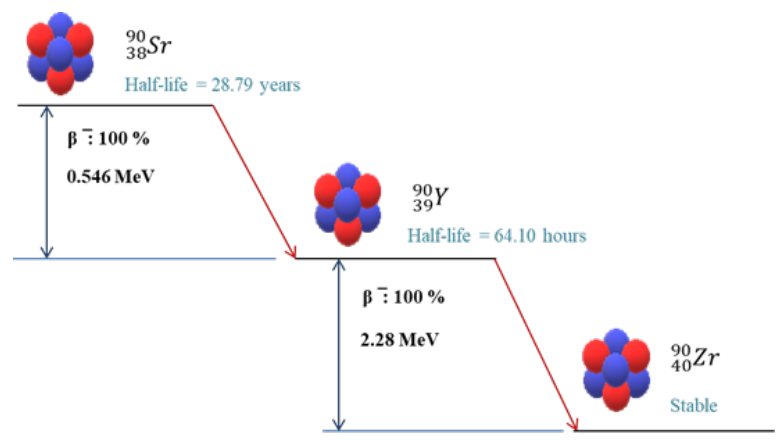

Figure 1. Decay scheme for ${ }^{\circ 0} \mathrm{Sr} / 9^{\circ} \mathrm{Y}$

In this work we examined a novel method of ${ }^{90} \mathrm{Y} /{ }^{\circ} \mathrm{Sr}$ separation in alkaline carbonate media. The main advantage of ${ }^{90} \mathrm{Y} /{ }^{\circ} \mathrm{Sr}$ separation in carbonate solution is avoiding handling difficulties and hazards of classical nitric acid extraction products. In addition, in this case, the analysis time is significantly reduced, since there is no need to wait for the ${ }^{90} \mathrm{Y} /{ }^{\circ 0} \mathrm{Sr}$ equilibrium to be reached. This method gives opportunity to use a selective solvent extraction agent for ${ }^{\circ} \mathrm{Y}$ and or ${ }^{90} \mathrm{Sr}$.

Carbonate media already became interesting in recent years for ${ }^{\circ} \mathrm{Y}$ and ${ }^{\circ} \mathrm{Sr}$ recovery: for example, functionalized $\quad p$-alkylcalix[8]arenes in perchloroethylene were examined as potential extractants of these radionuclides [15].

\footnotetext{
*igor smirnov@khlopin.ru
} 
Based on literature we screened different compounds, which are considered as promising yttrium extractants: 8-hydroxyquinioline (8-HQ) [16], azocomponds - pyridylazonaphthol (PAN) [17] pyridylazoresorcinol (PAR) [18], chromotropic acid and 2,3-dihydroxynaphthalene (2,3-DHN) (Fig. 2). Only 2,3-DHN and 8-HQ demonstrated sufficient extraction ability towards yttrium under these conditions. We also varied organic diluents (light and heavy) and studied butylacetate (BuAc), toluene and 2-nitrotoluene.<smiles>Oc1cccc2cccnc12</smiles>

(a)

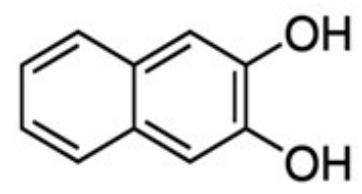

(b)
Figure 2. Potential yttrium extractants: (a) 8-HQ (b) 2,3-DHN

\section{MATERIALS AND METHODS}

\subsection{Reagents}

8-HQ, PAN, PAR, chromotropic acid and toluene were purchased from "Vekton" (Russia), 98.5\%-99.5\% 2,3-DHN was from SCHUHARDT MUNCHEB (Germany).

Butyl acetate and $\mathrm{SrCO}_{3}$ (analytical grade) were from "Reakhim" (Russia), 2-nitrotoluene was purchased from Lancaster (England), all organic diluents are analytical grade and used without any further purification.

Yttrium oxide was prepared by $\mathrm{Y}\left(\mathrm{NO}_{3}\right)_{3}$ decomposition at $800{ }^{\circ} \mathrm{C}$ for $1.5 \mathrm{~h}$ at muffle furnace.

Yttrium carbonate stock solution was prepared by dissolving its oxide in alkaline carbonate solutions $\left(\mathrm{Na}_{2} \mathrm{CO}_{3}, \mathrm{~K}_{2} \mathrm{CO}_{3}\right.$ and $\left.\left(\mathrm{NH}_{4}\right)_{2} \mathrm{CO}_{3}\right)$. All these salts were of analytical grade. For yttrium spectrophotometric determination Arsenazo III of analytical grade was used.

Radioactive isotopes ${ }^{90} \mathrm{Sr}$ and ${ }^{90} \mathrm{Y}$ were received from JSC Khlopin Radium Institute (Russia). Liquid scintillation cocktail Optiphase HiSafe 3 was purchased from PerkinElmer (USA).

\subsection{Apparatus and analysis}

The $\mathrm{pH}$ of aqueous phase was measured by $\mathrm{pH}$-meter Expert $\left( \pm 0.5^{\circ} \mathrm{C}, \mathrm{pX}(\mathrm{pH}) \pm 0.005, \mathrm{mV} \pm 0.2\right)$.

Stable yttrium isotope concentration was determined with Arsenazo III by standard spectrophotometric method $(l=10 \mathrm{~mm}, \lambda=650 \mathrm{~nm})$ using UV-2600 SHIMADZU UV-VIS spectrophotometer and double checked by emission spectrometer ICPE-9000 SHIMADZU, stable strontium isotope concentration was determined by emission spectrometer ICPE-900o SHIMADZU.
Radioactive isotopes ${ }^{90} \mathrm{Sr}$ and ${ }^{90} \mathrm{Y}$ were determined by liquid scintillation counting and Cherenkov counting standard methods using low level liquid scintillation spectrometer Quantulus 1220 (PerkinElmer).

\subsection{Procedure}

The dissolution rate was calculated using two-point standard method according to eq. 1 and eq. 2. To study yttrium dissolution rate we prepared a disk with a constant surface area: $0.03 \mathrm{~g}$ of $\mathrm{Y}_{2} \mathrm{O}_{3}$ transformed into the disk ( $6 \mathrm{~mm}$ - diameter and $0.4 \mathrm{~mm}$ - thickness) with the surface (S), expressed by eq. 3 :

$$
\begin{aligned}
& \Delta \mathrm{c} / \Delta \mathrm{t}=\mathrm{Vg} / \mathrm{s} \\
& \mathrm{V} / \mathrm{S}=\mathrm{Vg} / \mathrm{s} \cdot \mathrm{m}^{2} \\
& \mathrm{~S}=2 \pi \mathrm{r}^{2}+2 \pi \mathrm{rh}=2 \pi \mathrm{r}(\mathrm{r}+\mathrm{h})
\end{aligned}
$$

The kinetics experiments were conducted in $25 \mathrm{~mL}$ penicillin bottle for $120 \mathrm{~min}$ and $20 \mathrm{~mL}$ of each alkaline carbonate solutions.

The distribution ratios $(D)$ were determined as follows; $1 \mathrm{~mL}$ of each (aqueous and organic phase) was placed into the $4 \mathrm{~mL}$ centrifugal polypropylene tube, the two phase systems were shaken at $21 \pm 1{ }^{\circ} \mathrm{C}$ for $10 \mathrm{~min}$ (sufficient for a complete equilibrium, confirmed in our preliminary experiments).

In the stripping experiments, $0.8 \mathrm{~mL}$ of organic phase contacted with $0.8 \mathrm{~mL}$ of $\mathrm{HNO}_{3}$ solution (shaken at $21 \pm 1^{\circ} \mathrm{C}$ for $10 \mathrm{~min}$ ), then centrifuged at $3000 \mathrm{rpm}$ for $10 \mathrm{~min}$. The distribution ratios $(D)$ were expressed by eq. 4

$$
\mathrm{DY}=[\mathrm{Y}]_{\mathrm{org}} /[\mathrm{Y}]_{\mathrm{aq}}
$$

For stable yttrium extraction experiments the following system was chosen: " $0.01 \mathrm{~mol} / \mathrm{L}$ of $\mathrm{L}$ $(8-\mathrm{HQ} / 2,3-\mathrm{DHN})$ in organic phase $(\mathrm{BuAc} / 2-$ nitrotoluene) - $0.001 \mathrm{~mol} / \mathrm{L}$ of yttrium in $0.5 \mathrm{~mol} / \mathrm{L}$ $\mathrm{K}_{2} \mathrm{CO}_{3}$ aqueous solution", for ${ }^{90} \mathrm{Y} /{ }^{\circ} \mathrm{Sr}$ separation the following system was chosen: "0.001 mol/L of $\mathrm{L}$ (8$\mathrm{HQ} / 2,3-\mathrm{DHN}$ ) in organic phase (BuAc/2-nitrotoluene) $-4 \cdot 10^{-5} \mathrm{~mol} / \mathrm{L}$ of yttrium and $1 \cdot 10^{-6} \mathrm{~mol} / \mathrm{L}$ of strontium in $0.5 \mathrm{~mol} / \mathrm{L} \mathrm{K}_{2} \mathrm{CO}_{3}$ aqueous solution".

\section{RESULTS AND DisCUSSION}

\section{1. $\mathrm{Y}_{2} \mathrm{O}_{3}$ solubility and dissolution kinetics study}

The dissolution kinetics of $\mathrm{Y}_{2} \mathrm{O}_{3}$ solubility was studied using different alkaline carbonates agents (Tab. 1). Carbonates have staidly increased in dissolution kinetics in following order: $2 \mathrm{~mol} / \mathrm{L}$ $\left(\mathrm{NH}_{4}\right)_{2} \mathrm{CO}_{3}>>2 \mathrm{~mol} / \mathrm{L} \mathrm{K}_{2} \mathrm{CO}_{3}>2 \mathrm{~mol} / \mathrm{L} \mathrm{Na}_{2} \mathrm{CO}_{3}>>$ $1 \mathrm{~mol} / \mathrm{L}\left(\mathrm{NH}_{4}\right)_{2} \mathrm{CO}_{3}>1 \mathrm{~mol} / \mathrm{L} \mathrm{K}_{2} \mathrm{CO}_{3}>1 \mathrm{~mol} / \mathrm{L}$ $\mathrm{Na}_{2} \mathrm{CO}_{3}$.

Table 1 depicts yttrium solubility and dissolution kinetics, $1 \mathrm{~mol} / \mathrm{L} \mathrm{Na}_{2} \mathrm{CO}_{3}, \mathrm{~K}_{2} \mathrm{CO}_{3}$ and $\left(\mathrm{NH}_{4}\right)_{2} \mathrm{CO}_{3}$ possessed yttrium solubility $1.7,0.9,2.8 \mathrm{~g} / \mathrm{L}$ with dissolution rate of $0.21,0.26,0.24 \mathrm{~g} \cdot \mathrm{m}^{2} / \mathrm{s}$, respectively, $2 \mathrm{~mol} / \mathrm{L} \mathrm{Na} \mathrm{NO}_{3}, \mathrm{~K}_{2} \mathrm{CO}_{3}$ and $\left(\mathrm{NH}_{4}\right)_{2} \mathrm{CO}_{3}-4.9,1.4$, $8.2 \mathrm{~g} / \mathrm{L}$ and dissolution rate of $0.43,0.46,0.62 \mathrm{~g} \cdot \mathrm{m}^{2} / \mathrm{s}$, respectively. 
Table 1. Yttrium solubility and

dissolution kinetic studies in different alkaline agents

\begin{tabular}{|c|c|c|}
\hline Alkaline agent & Solubility, g/L & $\begin{array}{c}\text { Dissolution rate } \\
\text { V, g/s·m }\end{array}$ \\
\hline $1 \mathrm{~mol} / \mathrm{L} \mathrm{Na}_{2} \mathrm{CO}_{3}$ & $1.7 \pm 0.017$ & $0.213 \pm 0.025$ \\
\hline $2 \mathrm{~mol} / \mathrm{L} \mathrm{Na}_{2} \mathrm{CO}_{3}$ & $\mathbf{4 . 9} \pm \mathbf{0 . 0 9 6}$ & $\mathbf{0 . 4 3 0} \pm \mathbf{0 . 0 1 3}$ \\
\hline $1 \mathrm{~mol} / \mathrm{L} \mathrm{K}_{2} \mathrm{CO}_{3}$ & $0.9 \pm 0.031$ & $0.262 \pm 0.021$ \\
\hline $2 \mathrm{~mol} / \mathrm{L} \mathrm{K}_{2} \mathrm{CO}_{3}$ & $\mathbf{1 . 4} \pm \mathbf{0 . 0 2 9}$ & $\mathbf{0 . 4 5 8} \pm \mathbf{0 . 0 1 0}$ \\
\hline $1 \mathrm{~mol} / \mathrm{L}\left(\mathrm{NH}_{4}\right)_{2} \mathrm{CO}_{3}$ & $2.8 \pm 0.182$ & $0.243 \pm 0.026$ \\
\hline $2 \mathrm{~mol} / \mathrm{L}\left(\mathrm{NH}_{4}\right)_{2} \mathrm{CO}_{3}$ & $\mathbf{8 . 2} \pm \mathbf{1 . 0 1}$ & $\mathbf{0 . 6 2 2} \pm \mathbf{0 . 0 1 8}$ \\
\hline
\end{tabular}

3.2. Yttrium extraction and $Y / S r$ separation in alkaline carbonate media

Based on yttrium oxide solubility, we extracted yttrium from $\mathrm{Na}_{2} \mathrm{CO}_{3}, \mathrm{~K}_{2} \mathrm{CO}_{3}$ and $\left(\mathrm{NH}_{4}\right)_{2} \mathrm{CO}_{3}$ using extractants in different organic diluents.

Despite the fact that $\left(\mathrm{NH}_{4}\right)_{2} \mathrm{CO}_{3}$ showed the highest yttrium oxide solubility and dissolution rate, it demonstrated a poor yttrium extraction and distribution ratio $(D)$ (with the third phase formation). $\mathrm{K}_{2} \mathrm{CO}_{3}$ showed the lowest yttrium oxide solubility, but it had the highest yttrium distribution ratio $(D)$ with 8-HQ (in butyl acetate and 2-nitrotoluene), followed by $\mathrm{Na}_{2} \mathrm{CO}_{3}$. Therefore, $\mathrm{K}_{2} \mathrm{CO}_{3}$ was chosen for further extraction and separation studies. Only 8-HQ and 2,3-DHN demonstrated sufficient values of yttrium distribution ratios (Fig. 3).

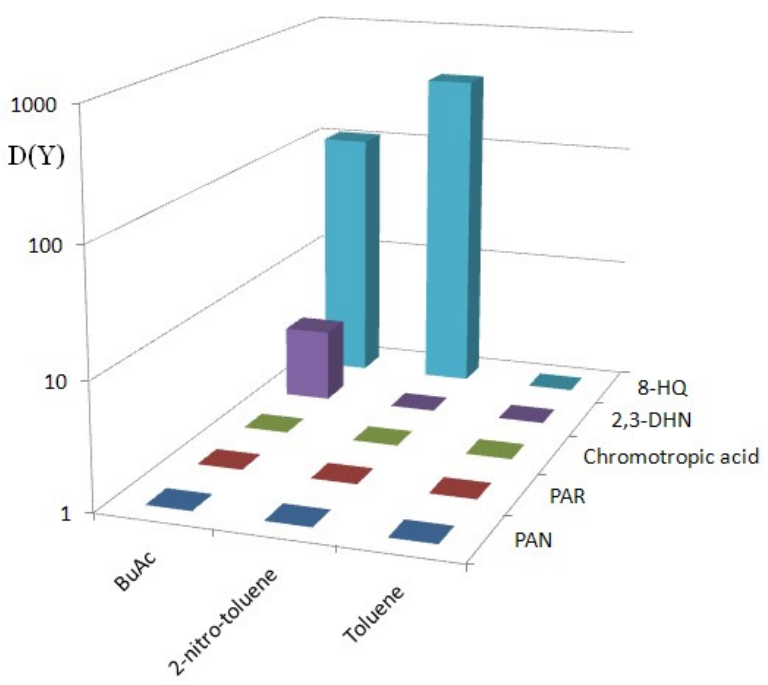

Figure 3. Comparison of extraction ability towards yttrium for potential extractants in different diluents:

8-hydroxyquinioline (8-HQ), pyridylazonaphthol (PAN), pyridylazoresorcinol (PAR), chromotropic acid and 2,3-dihydroxynaphthalene (2,3-DHN)

\subsubsection{Yttrium extraction}

8-HQ demonstrates that the value of yttrium distribution ratio depends on initial $\mathrm{pH}$ of the aqueous phase, $\mathrm{pH}$ gradually increases from 10 to 13.5 in 2-nitrotoluene and BuAc (Fig. 4).
Dy gradually increases after $\mathrm{pH} 10$ (8-HQ pKa: 9.9), in 2-nitrotoluene $\mathrm{pH} 13$ has maximum $\left(D_{\mathrm{Y}}\right)$ while in butyl acetate - $\mathrm{pH}$ 13.5. The $D_{\mathrm{Y}}$ decreases after $\mathrm{pH} 13$ in 2-nitrotoluene might be due to hydroxide precipitation and/or 8-HQ dissolution into aqueous phase. The $\lg D_{\mathrm{Y}}$ was 2.60 and 2.03 for 2-nitrotoluene and butyl acetate, respectively.

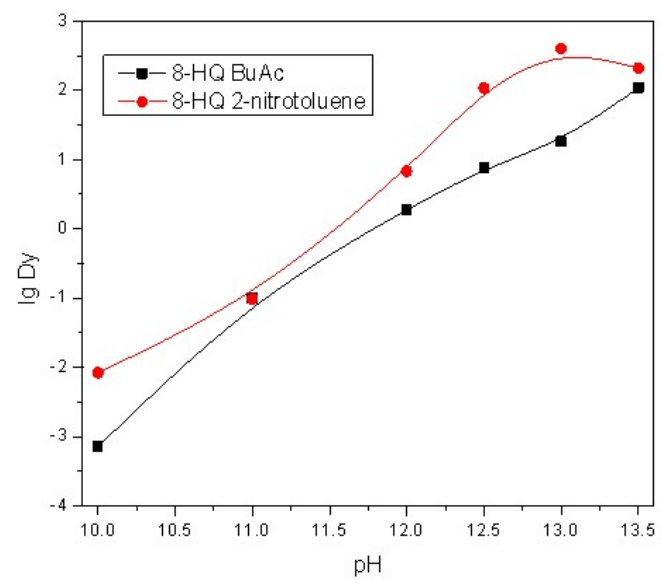

Figure 4. Effect of initial pH on yttrium extraction by 8-HQ

Organic phase saturation shows the limit ratio $[\mathrm{L}]:[\mathrm{M}] \sim 4$, which one can interpret as solvate composition ML4 (Fig. 5).

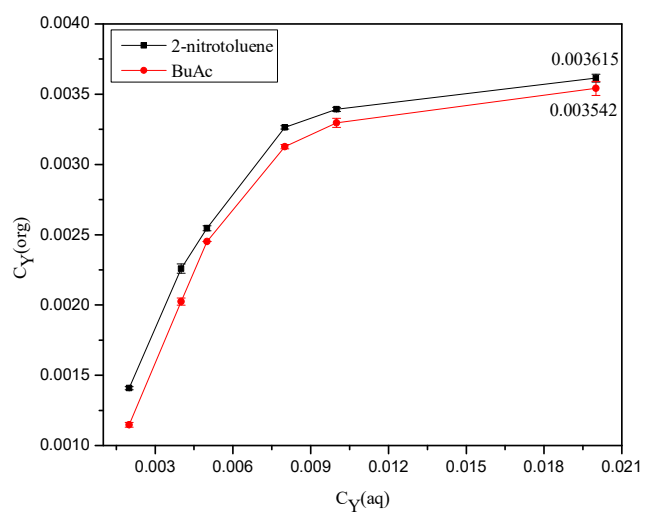

Figure 5. Correlation between yttrium concentrations in aqueous and organic phases in different diluents

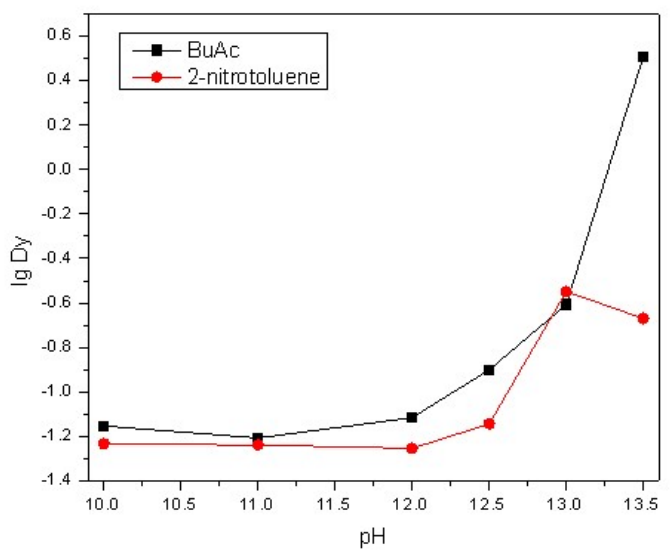

Figure 6. Effect of initial $\mathrm{pH}$ on yttrium extraction by 2,3-DHN 
Extraction with $2,3-\mathrm{DHN}$ demonstrates that the value of yttrium distribution ratio $D$ depends on initial $\mathrm{pH}$ of the aqueous phase, gradually increasing from $\mathrm{pH}$ 12 to $\mathrm{pH} 13.5$ in BuAc and to $\mathrm{pH} 13$ in 2-nitrotoluene (Fig. 6).

2,3-DHN showed acceptable $D_{\mathrm{Y}}$ in BuAc, whereas $D_{\mathrm{Y}}$ in 2-nitrotoluene is very low. This might be due to the 2,3 -DHN solubility in aqueous phase.

\subsubsection{Yttrium extraction and separation with $8 H Q$}

Extraction and separation of stable $\mathrm{Y}$ and $\mathrm{Sr}$ " $0.001 \mathrm{~mol} / \mathrm{L}$ of $8-\mathrm{HQ}-4 \cdot 10^{-5} \mathrm{~mol} / \mathrm{L}$ of yttrium and $1 \cdot 10^{-6} \mathrm{~mol} / \mathrm{L}$ of strontium in $0.5 \mathrm{~mol} / \mathrm{L} \mathrm{K}_{2} \mathrm{CO}_{3}$ aqueous solution were carried out (Fig. 7,8 ).

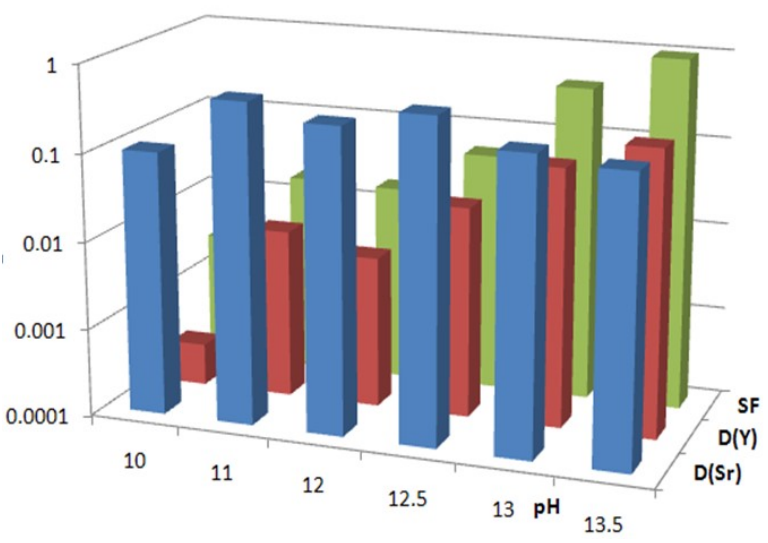

Figure 7. Y/Sr extraction and separation in BuAc

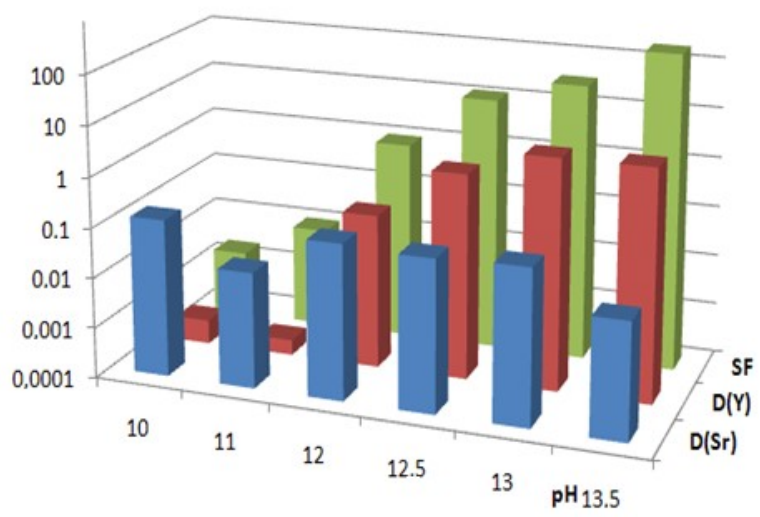

Figure 8. Y/Sr extraction and separation in 2-nitrotoluene

Figs. 7-8 demonstrate the values of SF in BuAc and 2-nitrotoluene. It is seen that for stable yttrium and strontium isotopes SF increases with $\mathrm{pH}$ and reaches its maximum values at $\mathrm{pH} 13.5$ in both BuAc and 2nitrotoluene. Yttrium is better extracted $\left(D_{\mathrm{Ymax}}=3.89\right)$ in 2-nitrotoluene. Maximum separation is observed in 2-nitrotoluene: $\mathrm{SF}=195$.

Extraction and separation experiments, carried out for radioactive ${ }^{90} \mathrm{Y}$ and ${ }^{90} \mathrm{Sr}$ confirmed the principal possibility of Y/Sr pair separation by solvent extraction with some features for trace amounts of radioactive isotopes (Fig. 9, 10).

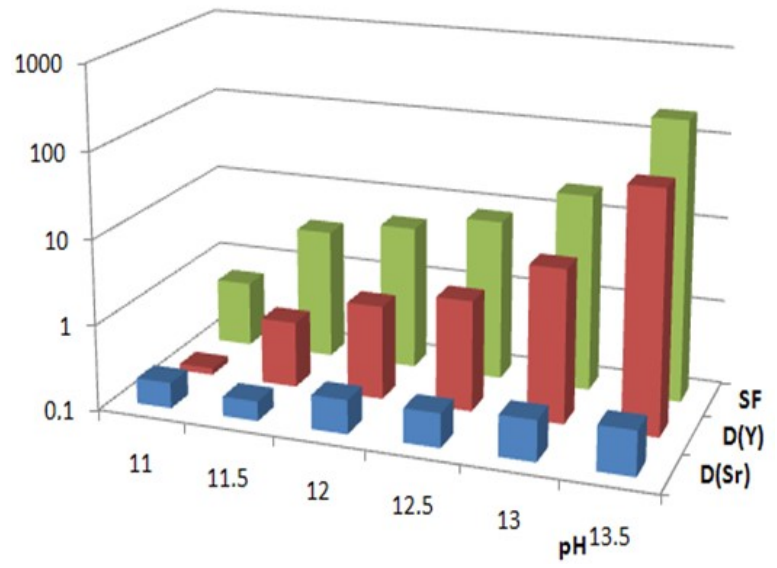

Figure 9. ${ }^{\circ} \mathrm{Y} /{ }^{\circ} \mathrm{Sr}$ extraction and separation in BuAc

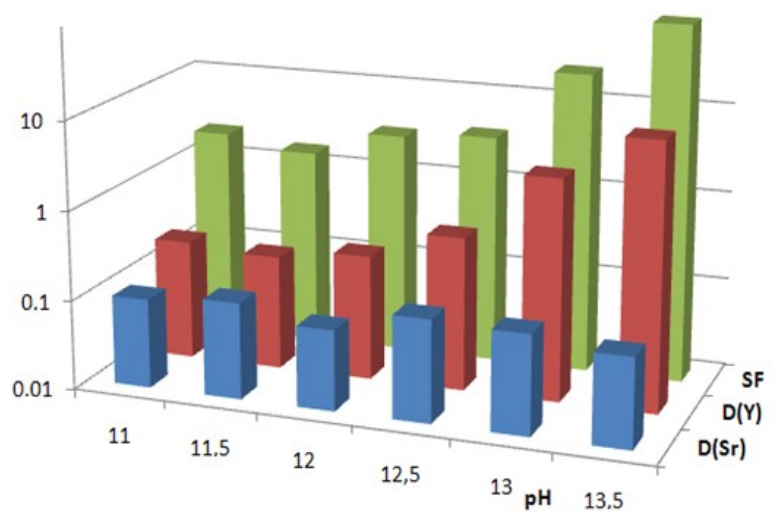

Figure 10. ${ }^{\circ 0} \mathrm{Y} /{ }^{\circ} \mathrm{Sr}$ extraction and separation in 2-nitrotoluene

The trend of SF dependence on $\mathrm{pH}$ is the same: it reaches maximum values at $\mathrm{pH}=13.5$ both for $\mathrm{BuAc}$ and 2-nitrotoluene. In contrast with the stable $\mathrm{Y}$ and $\mathrm{Sr},{ }^{\circ} \mathrm{Y}$ is extracted much better $\left(\mathrm{D}_{\max }>65\right)$ in BuAc. Maximum separation is observed in BuAc: SF $\sim 200$. The main results comparing two methods are presented in Tab. 2.

Table 2. Yttrium extraction and separation in different extraction systems $\left({ }^{*}\right.$ - measured radiometrically)

\begin{tabular}{|c|c|c|c|}
\hline \multirow{2}{*}{ Diluent } & \multicolumn{3}{|c|}{$8-\mathrm{HQ}$} \\
& $\mathrm{pH}=13.5$ \\
\cline { 2 - 4 } & $\mathrm{D}_{\mathrm{Y}}$ & $\mathrm{D}_{\mathrm{Sr}}$ & $\mathrm{SF}_{\mathrm{Y} / \mathrm{Sr}}$ \\
\hline \multirow{2}{*}{ BuAc } & 0.177 & 0.177 & 1 \\
& $65.7^{*}$ & $0.33^{*}$ & $200^{*}$ \\
\hline \multirow{2}{*}{ 2-nitrotoluene } & 3.89 & 0.02 & 195 \\
& $9.59^{*}$ & $0.1^{*}$ & $96^{*}$ \\
\hline
\end{tabular}

The similarity of extraction and separation data, obtained for stable and radioactive isotopes with 8-HQ, is evident for 2-nitrotoluene. Taking into account the different experimental methods, the values are very close. This confirms the principal possibility of $\mathrm{Y} / \mathrm{Sr}$ separation in carbonate media. The opposite situation for BuAc requires further investigation. 
The same experiments were carried out for 2,3-DHN, but the system with 2-nitrotoluene formed third phase, whereas for the system, based on BuAc, there were neither sufficient yttrium extraction, nor Y/Sr separation.

\section{CONCLUSION}

$\mathrm{Y} / \mathrm{Sr}$ extraction and separation in carbonate media with several ligands showed, that only 8-HQ and 2,3 -DHN can be regarded as perspective compounds for further studies.

The data obtained for stable and radioactive isotopes separation with 8-HQ revealed differences in the behavior of the extracted elements, which can be explained by differences in their concentrations (trace amounts for ${ }^{\circ} \mathrm{Y}$ and ${ }^{90} \mathrm{Sr}$ with the background of stable Y).

2,3-DHN demonstrated high solubility in aqueous phase with low values of distribution ratios, but it is still regarded as perspective after addition of modificator, preventing its transfer into aqueous phase.

Acknowledgements: The study was supported by the Russian Science Foundation (project No. 20-6346006). The researcher Ahmed Harb is funded by a scholarship under the joint executive program between the Arab Republic of Egypt and Russian Federation.

\section{REFERENCES}

1. R. Chakravarty, A. Dash, "Availability of Yttrium-90 from Strontium-90: A Nuclear Medicine Perspective," Cancer Biother. Radiopharm., vol. 27, no. 10, pp. 621-641, Dec. 2012. https://doi.org/10.1089/cbr.2012.1285

2. P. Pichestapong, W. Sriwiang, U. Injarean, "Separation of Yttrium-90 from Strontium-90 by Extraction Chromatography Using Combined $\mathrm{Sr}$ Resin and RE Resin," Energy Procedia, vol. 89, pp. 366-372, Jun. 2016.

https://doi.org/10.1016/j.egypro.2016.05.048

3. H. Tazoe et al., "Determination of strontium-90 from direct separation of yttrium-90 by solid phase extraction using DGA Resin for seawater monitoring," Talanta, vol. 152, pp. 219-227, May 2016. https://doi.org/10.1016/j.talanta.2016.01.065

4. N. Vajda, C.-K. Kim, "Determination of radiostrontium isotopes: A review of analytical methodology," Appl. Radiat. Isot., vol. 68, no. 12, pp. 2306-2326, Dec. 2010.

https://doi.org/10.1016/j.apradiso.2010.05.013

5. C. Xu, J. Wang, J. Chen, "Solvent Extraction of Strontium and Cesium: A Review of Recent Progress," Solvent Extr. Ion Exch., vol. 30, no. 6, pp. 623-650, Oct. 2012.

https://doi.org/10.1080/07366299.2012.700579

6. IAEA, "Production of Long Lived Parent Radionuclides for Generators: ${ }^{68} \mathrm{Ge},{ }^{82} \mathrm{Sr},{ }^{9} \mathrm{Sr}$ and 188W", Radioisot. Radiopharm. Ser. No. 2, Austria, Vienna: IAEA, 2010

Retrieved from:

https://www.iaea.org/publications/8268/production -of-long-lived-parent-radionuclides-for-generators68ge-82sr-9osr-and-188w

Retrieved on: July 15, 2021

7. D. W. Wester et al., "Large-scale purification of $90 \mathrm{~S}$ from nuclear waste materials for production of $90 \mathrm{Y}$, a therapeutic medical radioisotope," Appl. Radiat. Isot., vol. 59, no. 1, pp. 35-41, Jul. 2003. https://doi.org/10.1016/So969-8043(03)00151-9

8. D. F. Peppard, G. W. Mason, S. W. Moline, "The use of dioctyl phosphoric acid extraction in the isolation

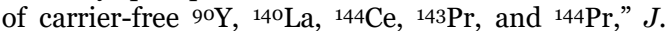
Inorg. Nucl. Chem., vol. 5, no. 2, pp. 141-146, 1957. https://doi.org/10.1016/0022-1902(57)80055-4

9. M. Y. Mirza, "A new method for the carrier-free production of $90 \mathrm{Y}$ from ${ }^{90} \mathrm{Sr}-90 \mathrm{Y}$ mixture and ${ }^{89} \mathrm{Sr}$ from neutron-irradiated $\mathrm{Y}_{2} \mathrm{O}_{3}$," Anal. Chim. Acta., vol. 40, pp. 229-233, 1968. https://doi.org/10.1016/So003-2670(00)86718-5

10. J. S. Wike, C.E. Guyer, D.W. Ramey, B.P. Phillips, "Chemistry for commercial scale production of yttrium-9o for medical research," Int. J. Radiat. Appl. Instrumentation. Part A. Appl. Radiat. Isot., vol. 41, no. 9, pp. 861-865, 1990. https://doi.org/10.1016/0883-2889(90)90064-N

11. K. Yoshizuka, Y. Sakamoto, Y. Baba, K. Inoue, F. Nakashio, "Solvent extraction of holmium and yttrium with bis(2-ethylhexyl)phosphoric acid," Ind. Eng. Chem. Res., vol. 31, no. 5, pp. 1372-1378, May 1992.

https://doi.org/10.1021/ieooo05a018

12. E. Anticó et al., "Solvent extraction of yttrium from chloride media by di(2-ethylhexyl)phosphoric acid in kerosene. Speciation studies and gel formation," Anal. Chim. Acta., vol.327, no. 3, pp. 267-276, 1996. https://doi.org/10.1016/0003-2670(96)00103-1

13. J. T. Chuang, J. G. Lo, "The solvent extraction of carrier-free $90 \mathrm{Y}$ from ${ }^{90} \mathrm{Sr}$ with crown ethers," $J$. Radioanal. Nucl. Chem. Artic., vol. 189, pp. 307-317, Jan. 1995. https://doi.org/10.1007/BFo2042610

14. E. P. Horwitz, W. W. Schulz, "Solvent Extraction in the Treatment of Acidic High-Level Liquid Waste: Where Do We Stand?”, in: Metal-Ion Separation and Preconcentration: Progress and Opportunities, A.H. Bond, M.L. Dietz, R.D. Rogers, Eds., Washington, DC, USA, ACS Symposium Series, American Chemical Society, 1999, ch. 3, pp. 20-50. https://doi.org/10.1021/bk-1999-0716.choo3

15. I.V. Smirnov, V.S. Shirokova, A.Z. Yumaguen, M.V. Logunov, "Extraction of Strontium and Yttrium from Alkaline Carbonate Media with Functionalized Calix[8]arenes", Radiochemistry, vol. 60, pp. 248-254, Jun. 2018.

Retrieved from:

https://www.readcube.com/articles/10.1134\%2Fs106 6362218030050

Retrieved on: July 15, 2021

16. G. Cote, D. Bauer, "Liquid-liquid extraction of germanium with oxine derivatives," Hydrometallurgy, vol. 5, no. 2-3, pp. 149-160, Feb. 1980.

https://doi.org/10.1016/0304-386X(80)90035-3

17. S. Shibata, "Spectrophotometric determination of rare earth metals with 1-(2-pyridylazo)-2-naphthol," Anal. Chim. Acta, vol. 28, pp. 388-392, 1963. https://doi.org/10.1016/So003-2670(00)87250-5

18. L. Sommer, H. Novotná, "Complexation of aluminium, yttrium, lanthanum and lanthanides with 4-(2-pyridylazo)resorcinol (par)," Talanta, vol. 14, no. 4, pp. 457-471, Apr. 1967. https://doi.org/10.1016/0039-9140(67)80072-9 